\title{
시각신경 $\mathrm{MR}$ 검사 시 다중 각도 스캔 기법의 유용성 평가
}

\author{
조무성*, 조재환, 배재영**, 김정수**, 김경근**** \\ 경산1대학 방사선과*, 계명대학교 화학과**, $\mathrm{GE}$ healthcare ${ }^{* * *}$, 대구산업정보대학 방사선과****
}

\section{Evaluation of usefulness of multi directional angles oblique scan method in optic nerve MRI}

\author{
MooSeong $\mathrm{Cho}^{*}$, Jaehwan $\mathrm{Cho}^{*}$, Jaeyeong Bae ${ }^{* *}$, Jeongsoo Kim ${ }^{* * *}$, Kyeongkeun Kim ${ }^{* * * *}$ \\ Department of Radiological Science, Gyeonesan University College*, Department of Chemistry, Keimyung University**, \\ GE healthcare ${ }^{* * *}$, Department of Radiological Science, Daegu Polytechnic College University ${ }^{* * * *}$
}

\section{요야}

본 연구는 입체적 분포를 형성한 시각신경계에 대하여 MRI 시스템의 경사자기장으로써 하나의 스캔 대상단면을 3 차원 형태의 여러 방향으로 향하게 하는 다중사위 스캔각도의 변화에 관하여 실험하였고 기존의 단순각도 사방향 검사 방법과 비교 고찰 하였다. 입체적 분포를 이루는 뇌의 시각신경계에 대하여 $\mathrm{MR}$ 시스템의 경사자기장으로써 국내 정상 성인을 대상으로 시각신경의 사위영상화를 위한 기존의 사위(시상-관상단면) 스캔방법과 다중사위(시상-관상-횡단 면) 스캔각도의 변화를 실험하였다. 그 결과 다중각도를 이용한 사위스캔 방법이 기존의 스캔방법에 비해 더 넓은 영 역의 해부학적 정보를 나타내는 것을 영상으로 확인하였다. 또한 시각신경을 명료하게 나타내기 위해서는 영상단면두 께와 펄스시퀀스의 선택도 고려되어야할 것으로 확인 되었다.

중심단어: 펄스계열, 다중사위스캔 각도, 시신경

\begin{abstract}
This research experimented on the change of the multiple colleague scan angle facing one scan object facet to many directions of the form of 3D about the visual angle nervous system forming the cubic distribution with the gradient magnetic field of the mri system and considered the existing basic angle oblique direction test coverage and comparison. MR system can freely select various pulse sequence and image slice. To oblique imaging for optic nerve viewing, we have studied the variation of scan angle between typical oblique scan method (sagittal-coronal plane) and multi directional angles oblique scan method ( sagittal-coronal-axial plane) using gradient of MR system. In this study, the subjects of the experiment were normal adults in our country. As a result, we confirmed that multi directional angles oblique scan method can display anatomical information of more wider area than typical oblique scan method. In addition, to clearly display optic nerve, we also confirmed that image slice thickness and pulse sequence have effect on it.
\end{abstract}

Key words : pulse sequence, multi directional angles oblique, optic nerve 


\section{I. 서론}

의료영상기기의 발전과 함께 검사방법도 다양하게 발전되었다. 정확한 진단을 위한 의료영상검사 및 결 과를 얻기 위해서 원칙적으로는 인위적으로 환자의 형태적 해부구조와 내부정보를 왜곡하지 않고 최대한 많이 얻는 것이다. 그러나 인체는 해부구조상 굴곡 되 거나 3 차원적 입체구조를 형성하여 조직이 교차 또는 중첩되는 등 복잡한 형태를 이루고 있기 때문에 2차원 적 평면영상으로 모두 나타내기는 쉽지 않다. 이러한 부위는 경우에 따라서 그 구조를 관찰하기 쉽게 하기 위해 가능한 마치 평면위에 펼쳐놓은 것처럼 묘출하 기위한 방법이 다양하게 연구되어왔으며 대표적인 것 으로서 치아의 파노라마 촬영술 (panoramic tomography) 등이 있다 ${ }^{[1]}$. 중추시각계에 관한 연구는 주 로 사람과 유사한 기능을 가진 동물을 대상으로 실험 되어왔다. 시각신경 (optic nerve)들은 좌.우 안구에 시 신경원반으로부터 나와 안구공 내부의 안구 뒤쪽 두 꺼운 조직을 따라 통과하여, 두개골 밑쪽의 시신경공 (optic foramen)을 지난다. 양쪽 눈의 신경절세포의 축 삭돌기가 망막을 출발하여 뇌간에 시냅스를 형성하기 전까지 전해지는 주요 시각경로는 시각신경과 시신경 교차 (optic chiasma) 그리고 시각로 (optic tract)의 세 가 지 구조를 통하게 된다 ${ }^{[2]}$. 시각과 관련된 영상정보를 Roentgen 선(X-ray)으로써 얻기 위한 방법 중에는 골격 구조인 시신경공을 촬영하여 제한적으로 관찰하는 방 법이 있다 ${ }^{[2]}$. 또 전산화단층촬영 (computed tomography, $\mathrm{CT}$ )을 이용한 시각신경 영상은 기기 구성상 스캔각도 (scan angle)의 제한 때문에 단순히 횡단면상으로써 관 찰한다. 수학적 계산에 의한 시상단면 영상화방법이 있지만 제한적으로 묘출되며 뼈와 주변조직과의 흡수 차이에 의해서 영상의 관심부위에 인공물 (artifact)를 남길 수 있고, 연부조직의 해상력이 낮은 단점도 있다 [3]. 그러나 자기공명영상 (magnetic resonance image, $\mathrm{MRI}$ )은 CT 영상보다 연부조직의 해상력이 높고 다양 한 펄스 시퀀스 (pulse sequence)와 공간좌표상의 축 (x, $\mathrm{y}, \mathrm{z}$ ) 방향으로 설치된 편차 (경사)자기장 코일 (gradient coil: $\mathrm{Gx}, \mathrm{Gy}, \mathrm{Gz}$ )을 이용하여 영상단면을 자유롭게 선 택할 수 있는 장점이 있다. 안구를 포함한 시각신경계 의 영상해부학적 관찰범위는 대략 시각신경, 시신경교
차, 의료영상기기의 발전과 함께 검사방법도 다양하게 발전되었다. 정확한 진단을 위한 의료영상검사 및 결 과를 얻기 위해서 원칙적으로는 인위적으로 환자의 형태적 해부구조와 내부정보를 왜곡하지 않고 최대한 많이 얻는 것이다. 그러나 인체는 해부구조상 굴곡 되 거나 3 차원적 입체구조를 형성하여 조직이 교차 또는 중첩되는 등 복잡한 형태를 이루고 있기 때문에 2차원 적 평면영상으로 모두 나타내기는 쉽지 않다. 이러한 부위는 경우에 따라서 그 구조를 관찰하기 쉽게 하기 위해 가능한 마치 평면위에 펼쳐놓은 것처럼 묘출하 기위한 방법이 다양하게 연구되어왔으며 대표적인 것 으로서 치아의 파노라마 촬영술 (panoramic tomography) 등이 있다 ${ }^{[1]}$. 중추시각계에 관한 연구는 주로 사람과 유사한 기능을 가진 동물을 대상으로 실 험되어왔다. 시각신경 (optic nerve)들은 좌.우 안구에 시신경원반으로부터 나와 안구공 내부의 안구 뒤쪽 두꺼운 조직을 따라 통과하여, 두개골 밑쪽의 시신경 공 (optic foramen)을 지난다. 양쪽 눈의 신경절세포의 축삭돌기가 망막을 출발하여 뇌간에 시냅스를 형성하 기 전까지 전해지는 주요 시각경로는 시각신경과 시 신경교차 (optic chiasma) 그리고 시각로 (optic tract)의 세 가지 구조를 통하게 된다 ${ }^{[2]}$. 시각과 관련된 영상정 보를 Roentgen 선(X-ray)으로써 얻기 위한 방법 중에는 골격구조인 시신경공을 촬영하여 제한적으로 관찰하 는 방법이 있다 ${ }^{[2]}$. 또 전산화단층촬영 (computed tomography, CT)을 이용한 시각신경 영상은 기기 구성 상 스캔각도 (scan angle)의 제한 때문에 단순히 횡단면 상으로써 관찰한다. 수학적 계산에 의한 시상단면 영 상화방법이 있지만 제한적으로 묘출되며 뼈와 주변조 직과의 흡수차이에 의해서 영상의 관심부위에 인공물 (artifact)를 남길 수 있고, 연부조직의 해상력이 낮은 단 점도 있다 ${ }^{[3]}$. 그러나 자기공명영상 (magnetic resonance image, MRI)은 CT 영상보다 연부조직의 해상력이 높고 다양한 펄스 시퀀스 (pulse sequence)와 공간좌표상의 축 $(\mathrm{x}, \mathrm{y}, \mathrm{z})$ 방향으로 설치된 편차 (경사)자기장 코일 (gradient coil: Gx, Gy, Gz)을 이용하여 영상단면을 자유 롭게 선택할 수 있는 장점이 있다. 안구를 포함한 시 각신경계의 영상해부학적 관찰범위는 대략 시각신경, 시신경교차, 시각 로, 가쪽 무릎체 (lateral geniculate body) 그리고 시각 로 부챗살 (optic radiation) 뿐만 아 
니라, 검사기기의 발전과 함께 기능적 $\mathrm{MRI}$ 시스템을 이용하여 생리적 변화의 측정도 활발히 연구되고 있 다 ${ }^{[2]}$. MRI를 이용한 안와 또는 시각신경계의 영상검사 는 일반적으로 횡 (transverse: Tra, axial) 단면, 관상 (coronal: Cor) 단면, 시상 (sagittal: Sag) 단면, 시상단면 사위스캔 (oblique scan)의 영상을 각각 획득하여 관찰 하고 있다 ${ }^{[4]}$. 필요에 따라서는 안와 주위의 지방조직 에서 발생하는 신호를 억제 (지방 신호억제, fat suppression: fs)하는 펄스 시퀀스를 이용하여 종합정보 를 분석 한다 ${ }^{[5]}$ 하지만 인체 시신경계의 횡단면 영상 은 시신경계 해부구조의 위치가 각각 다르기 때문에 각 단면의 영상에서 일부 제한적으로 나타나고 또 영 상 단면의 간격에 의해 정보의 손실이 발생한다. 이에 본 연구는 입체적 분포를 형성한 시각신경계에 대하 여 MRI 시스템의 경사자기장으로써 하나의 스캔 대상 단면을 3차원 형태의 여러 방향으로 향하게 하는 다중 사위 스캔각도의 변화에 관하여 실험하였고 기존의 단순각도 사방향 검사 방법과 비교 고찰 하였다.

시각 로, 가쪽 무릎체 (lateral geniculate body) 그리고 시각 로 부챗살 (optic radiation) 뿐만 아니라, 검사기기 의 발전과 함께 기능적 MRI 시스템을 이용하여 생리 적 변화의 측정도 활발히 연구되고 있다 ${ }^{[2]}$. MRI를 이 용한 안와 또는 시각신경계의 영상검사는 일반적으로 횡 (transverse: Tra, axial) 단면, 관상 (coronal: Cor) 단면, 시상 (sagittal: Sag) 단면, 시상단면 사위스캔 (oblique scan)의 영상을 각각 획득하여 관찰하고 있다 ${ }^{[4]}$. 필요 에 따라서는 안와 주위의 지방조직에서 발생하는 신 호를 억제 (지방 신호억제, fat suppression: fs)하는 펄스 시퀀스를 이용하여 종합정보를 분석 한다 ${ }^{[5]}$ 하지만 인 체 시신경계의 횡단면 영상은 시신경계 해부구조의 위치가 각각 다르기 때문에 각 단면의 영상에서 일부 제한적으로 나타나고 또 영상 단면의 간격에 의해 정 보의 손실이 발생한다. 이에 본 연구는 입체적 분포를 형성한 시각신경계에 대하여 MRI 시스템의 경사자기 장으로써 하나의 스캔 대상단면을 3 차원 형태의 여러 방향으로 향하게 하는 다중사위 스캔각도의 변화에 관하여 실험하였고 기존의 단순각도 사방향 검사 방 법과 비교 고찰 하였다.

\section{II. 대상 및 방법}

\section{1. 두부외형의 실측과 피험자 선택기준}

동양인의 두상은 일반적으로 서양인에 비해서 외견 상 전후가 짧고, 얼굴은 좌우로 넓은 형태이다. 입체구 조를 이루고 있는 시각신경에 대하여 두개골 내부의 평균크기를 실측하는 것이 사실적이지만 현실상 어렵 기 때문에 다중각도 사위스캔의 개인별 오차를 줄이 기 위해서는 일정한 기준을 두고 스캔각도를 구할 필 요가 있다. 시각신경의 다중각도 사위스캔의 기준을 확보하기위한 기초자료는 $S$ 병원 신경외과에 내원한 국내의 성인 (연령: 20 70세, 남: 30 명, 여: 20 명)을 대 상으로 두개골 외형을 실측한 자료로부터 두부의 외 부 크기를 측정하였고, 연구의 편의상 측정 평균치에 해당하는 사람을 대상으로 실험하였다.

\section{2. 입체적 관측을 위한 뇌 횡단면 스캔}

시각신경계의 해부구조에 대한 입체적 공간정보를 관찰하여 다중사위스캔 각도의 설정에 참고하기위해 인체의 두부 횡단면을 스캔하였다. 시각신경 사위방향 스캔각도의 오차를 줄이기 위해 한국인의 평균치에 해당하는 성인 남성을 대상으로 하였다. 목적부위의 기본계획영상에 사용하기위해 시상단면, 관상단면, 횡 단면을 스캔하였다. 시각신경 사위방향 스캔계획에 이 용할 두부 횡단면 기준영상은 시상단면상으로부터 앞 맞교차 (anterior commissure, $\mathrm{AC}$ )와 뒤맞교차 (posterior commissure, $\mathrm{PC}$ )를 연결한 직선과 평행하고, 관상단면 상에서 조정하여 뇌의 좌우가 대칭을 이루게 하였다. $\mathrm{MRI}$ 영상은 $1.5 \mathrm{~T}$ 초전도형 자기공명영상 시스템 (Magnetom Symphony, Siemens, Germany) 및 두부 전용 coil을 이용하였다. 스캔 시퀀스는 빠른 스핀에코 (fast spin echo: FSE) T2강조영상 (T2 weighted image: T2WI) 을 얻기 위해 반복시간 (repetition time: TR)을 2,300 ms, 에코시간 (echo time: TE)을 $82 \mathrm{~ms}$ 로하고 가산평균 회 수를 1 번으로 하여 스캔 하였다.

\section{3. 다중각도 사위스캔의 각도설정과 영상변화 실험}

다중사위영상을 보기위한 스캔계획은 MRI 시스템 
의 단면선택 경사자기장 (gradient coil: Gx, Gy, Gz)을 이용하여 두부의 정중시상단면과 시각신경이 이루는 접선을 Rhese method에서와 같은 기본각도 $\left(37^{\circ}\right)$ 로 정 하고 전체적으로 시상단>관상단>횡단면 $(\mathrm{Sag}>\mathrm{Cor}>$ $\mathrm{Tra}$ ) 방향으로 각도를 변화하였다. 단면 경사각도의 부 호는 경사방향을 우측으로 기울인 경우에 양 $(+)$ 의 수 로 표시하였다. 다중사위방향 스캔계획의 기본영상으 로는 각도의 정확도를 높이기 위해서 횡단면 영상 중 에 시각신경이 명료하게 나타난 영상을 선택하였다. 두부의 정중 시상선과 시각신경이 이루는 사위방향의 기준선으로부터 스캔 대상 측의 시각신경과 시신경교 차 및 시각경로의 구조를 가장 많이 포함하는 상태에 서 직선되게 하여 스캔 각도를 설정하였다. 첫 번째는 MRI 시스템의 컴퓨터 화면상에서 목적 영상단면의 중 심선이 기준선에 겹치도록 조절하고 스캔대상 시신경 계가 포함될 수 있도록 예상하는 방향으로 각도를 입 력하였다. 두 번째는 시각신경의 일부가 나타난 관상 단면 영상 (coronal image)에서 목적부위가 잘 나타날 수 있도록 해당하는 방향으로 단면을 기울인 상태에 서 단면중심이 기준선인 시각신경을 경유하도록 미세 조정을 하였다. 세 번째는 시상단면 영상에서 상.하방 향의 각도를 조절하여 시각경로와 시방선 부위가 포 함될 수 있는 대각선 방향으로 조절하였다. 이 경우에 는 횡단면과 관상단면 계획영상에서 스캔계획 영상단 면 중심선의 변화가 있는지 관찰하였고, 차이가 있을 경우에는 공간좌표상의 각도를 교정하여 시각신경 구 조가 영상단면 내에 포함되게 하였다. 이상의 시각신 경계 구조의 다중각도 사위스캔 방법을 'Cho method' 로 정하고 적정의 스캔각도를 설정하기 위해 Table 1 과 같이 실험하고 영상을 확인하였다. 펄스 시퀀스는 FSE로써 TR $(2,000 \mathrm{~ms}), \mathrm{TE}(82 \mathrm{~ms})$ 를 선택하여 T2WI (No. 1 4) 및 지방 신호억제 T2WI (T2WI-fs) 방법 (No. 5 6)을 이용하였고, 가산평균횟수는 1번으로 하고, 영 상단면의 두께는 해상도를 고려하여 $3 \mathrm{~mm}$ 로 선택하 였다. 각각의 실험에서 스캔각도는 MRI 시스템에 내 장된 프로그램을 사용하였고, 완성된 MRI 영상의 관 찰은 $\pi$-view star (Infinitt Corp., Korea) 프로그램을 이용 하였다.
Table 1. Experiment on image change and multi oblique scan angle of human optic nerve using MRI.

\begin{tabular}{|c|c|c|c|c|c|}
\hline $\begin{array}{c}\text { Scan } \\
\text { No }\end{array}$ & $\begin{array}{c}\text { Scan } \\
\text { port } \\
\text { ion }\end{array}$ & $\begin{array}{l}\text { Slice sectional } \\
\text { angle }\end{array}$ & $\begin{array}{c}\text { Sequenc } \\
\mathrm{e}\end{array}$ & $\begin{array}{l}\text { Thick } \\
(\mathrm{mm})\end{array}$ & $\begin{array}{l}\text { Scan } \\
\text { method }\end{array}$ \\
\hline 1 & Rt & $\operatorname{Sag}>\operatorname{Cor}\left(37^{\circ}\right)>\operatorname{Tra}\left(21^{\circ}\right)$ & \multirow{4}{*}{ FSE-TZWI } & \multirow{6}{*}{3} & \multirow{6}{*}{$\begin{array}{l}\text { Multi } \\
\text { angle } \\
\text { ob l ique } \\
\text { (Cho } \\
\text { method) }\end{array}$} \\
\hline 2 & Rt & $\operatorname{Sag}>\operatorname{Cor}\left(39^{\circ}\right)>\operatorname{Tra}\left(23^{\circ}\right)$ & & & \\
\hline 3 & Rt & Sag $>$ Cor $\left(42^{\circ}\right)>\operatorname{Tra}\left(25^{\circ}\right)$ & & & \\
\hline 4 & Rt & Sag $>\operatorname{Cor}\left(46^{\circ}\right)>\operatorname{Tra}\left(27^{\circ}\right)$ & & & \\
\hline 5 & Rt & $\operatorname{Sag}>\operatorname{Cor}\left(40^{\circ}\right)>\operatorname{Tra}\left(28^{\circ}\right)$ & \multirow{2}{*}{$\begin{array}{l}\text { FSE-T2WI } \\
-f S\end{array}$} & & \\
\hline 6 & Rt & $\begin{array}{c}\operatorname{Sag}>\operatorname{Cor}\left(40^{\circ}\right)>\operatorname{Tra} \\
\left(-28^{\circ}\right)\end{array}$ & & & \\
\hline
\end{tabular}

\section{4. 기존방법과 Cho method의 비교}

우측의 시각신경계 사위영상을 보기위한 기존의 스 캔방법 (No. 1)과 다중각도사위스캔 방법을 이용한 Cho method (No. 2 3)의 좌·우 양측의 영상을 모두 비 교하기위해 실험한 스캔조건을 Table 2에 기록하였다. 영상화 펄스 시퀀스는 스핀에코 (spin echo: SE) T1강 조영상 (T1 Weighted image: T1WI)에 지방 신호억제(fs) 방법을 이용하였다. 이 실험에서는 가산평균횟수를 2 번으로 하고, 영상단면의 두께도 $4 \mathrm{~mm}$ 로 하여 SNR를 증가되게 하였다. 세부적 스캔각도의 조정은 (실험 3) 의 방식과 동일하게 하였다. 기존의 방법은 두부의 정 중 시상단면으로부터 시신경교차점을 중심으로 스캔 계획단면을 좌표상의 $\mathrm{xy}$ 축 방향 (우측 또는 좌측)으로 시각신경이 곧게 뻗어있는 한 방향으로만 각도를 형 성하도록 회전하여 스캔하는 하였고 Cho method 방법 은 두부의 정중시상단면으로부터 스캔계획 영상단면 을 시각신경계의 전체 해부구조를 포함하는 여러 방 향으로 경사각을 이루게 하여 다중사위 스캔을 하였 다. 
Table 2. Comparison conventional method with Cho method for observing optic nerve system.

\begin{tabular}{|c|c|c|c|c|c|}
\hline $\begin{array}{c}\text { Scan } \\
\text { No }\end{array}$ & $\begin{array}{c}\text { Scan } \\
\text { port } \\
\text { ion }\end{array}$ & Slice sectional angle & $\begin{array}{l}\text { Sequ } \\
\text { ence }\end{array}$ & $\begin{array}{l}\text { Slice } \\
\text { thick }\end{array}$ & $\begin{array}{l}\text { Scan } \\
\text { method }\end{array}$ \\
\hline 1 & $\mathrm{Rt}$ & Sag $>\operatorname{Cor}\left(37^{\circ}\right)$ & $\begin{array}{c}\text { SE-T } \\
1 W I- \\
\text { fS }\end{array}$ & $4 \mathrm{~mm}$ & $\begin{array}{c}\text { Convent } \\
\text { ional } \\
\text { method }\end{array}$ \\
\hline 2 & Rt & $\begin{array}{c}\text { Sag }>\text { Cor }\left(41^{\circ}\right)>\operatorname{Tra} \\
\left(29^{\circ}\right)\end{array}$ & \multirow{2}{*}{$\begin{array}{c}\text { SE-T } \\
1 W I- \\
\text { fS }\end{array}$} & \multirow{2}{*}{$4 \mathrm{~mm}$} & \multirow{2}{*}{$\begin{array}{l}\text { Cho } \\
\text { method }\end{array}$} \\
\hline 3 & $\mathrm{Lt}$ & $\begin{array}{c}\text { Sag }>\text { Cor }\left(-38^{\circ}\right)>\operatorname{Tra} \\
\left(-29^{\circ}\right)\end{array}$ & & & \\
\hline
\end{tabular}

\section{III. 결과}

\section{1. 두부외형의 실측 및 기준}

한국인의 성인 두개골 외형을 실측한 자료의 조사 결과에 의하면 두개골 전후 (측정부위: 이마-후두골)의 평균은 약 $19.5 \pm 1 \mathrm{~cm}$ 이고, 좌우 (측정부위: 좌·우측 두 정부간 넓이)의 평균은 약 $16.5 \pm 0.5 \mathrm{~cm}$ 로 나타났으며 남성이 여성보다 전·후, 좌·우 모두 평균적으로 약 1 $\mathrm{cm}$ 더 큰 것으로 조사되었다.

\section{2. 횡단면 스캔과 해부구조의 관측}

Fig. 1은 두부의 MRI 횡단면 영상을 나타낸 것이다. 성인 남성의 뇌 횡단면을 스캔한 MRI 영상으로부터 시각신경계의 해부구조를 관찰하여 기하학적 관계를 가늠하기위해 6매의 시각신경계 부위를 별도로 나타 낸 영상이다 $(\mathrm{A} \sim \mathrm{F})$. 이 영상으로부터 시각신경은 시신 경교차점을 기준하여 시각신경과 시각 로 및 가쪽 무 릎체 그리고 시각 로 부챗살 (시방선)로 이어진 신경 섬유들의 입체적 관계를 추정할 수 있다. 시각신경계 구조가 나타난 이들 영상을 위로부터 순서대로 나열 하면 해부학적 자세에서 시각 로 부챗살은 가장 높은 위치에 출현하여 후방까지 넓은 영역으로 펼쳐져 보 인다 (A D). 다음으로는 시각 로 및 가쪽 무릎체 일부 로 추정되는 해부구조를 나타내고 있다 $(\mathrm{B}, \mathrm{C})$. 가장 하부의 영상은 부분체적효과에 의한 일부의 시각신경 과 함께 시신경교차가 나타나있다 $(\mathrm{E}, \mathrm{F})$. 이 영상은 뇌의 좌.우 대칭구조와 시각신경의 전방을 잘 보여주
고 있지만, 시신경교차점의 후방과 가쪽무릎체는 보이 지 않는다. 이 때문에 임상에서는 대부분 시각신경 주 위의 상.하 구조를 잘 보여줄 수 있는 시상단면 사위 스캔영상을 기본적으로 포함해서 관찰한다 ${ }^{[6]}$.

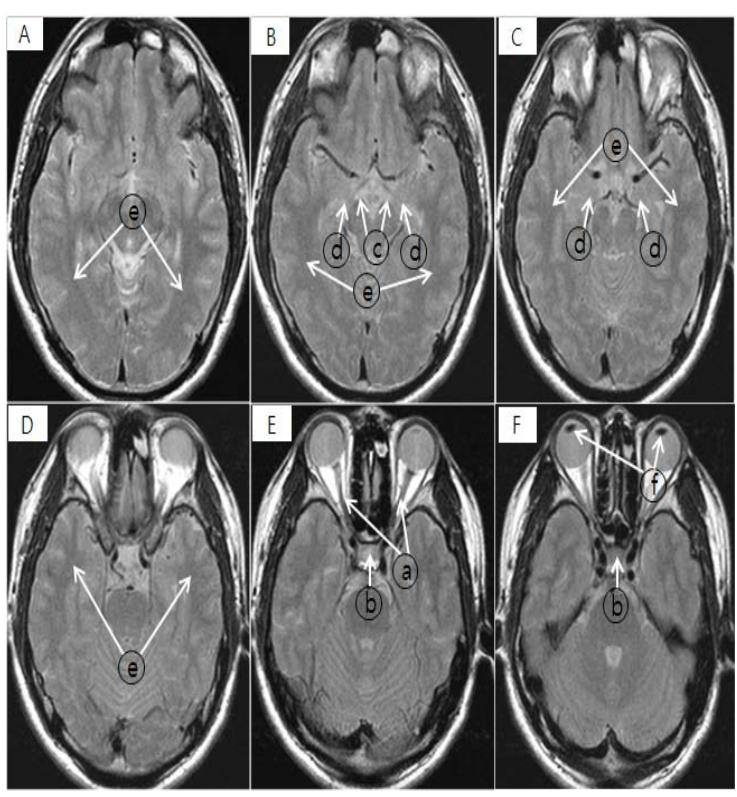

Fig. 1. Anatomic arrangement of scan images from MRI of brain transverse plane $\left(A^{\sim} F\right)$. (a): optic nerve, (b): optic chiasma, (c): optic tract, (d): geniculate body, (e): optic radiation, (f): Lens

Fig. 2는 상기의 영상과 입체적으로 비교하기위해 시각신경계의 3 차원 모형과 평면 모식도를 좌우로 배 열하였다. (A)는 연구대상인 인체의 뇌 조직 가운데 시 각신경계에 대한 입체모형 사진으로서 안구로부터 시 각부챗살에 이르기까지 교차 굴곡한 전체 신경전달 경로를 사실적으로 보여주고 있다 ${ }^{[7]}$. (B)는 시각신경계 의 평면해부구조를 관찰하기위해 Fig. 1의 MR 영상 중 에 5 매 (A-E)의 횡단면영상을 합성하여 나타낸 것이며 영상 내의 점선은 합성한 부분의 표시이다. 이 영상을 그림 $(\mathrm{A})$ 와 비교하면 시각신경 전체를 2차원 평면상에 서 쉽게 형태를 파악할 수 있으며, 영상 내에서 해부 구조가 단절된 것으로 보아서 $10 \%$ 의 단면간격에 의한 정보손실을 감지할 수 있다. $(\mathrm{C})$ 는 시각계의 기능과 시 각경로의 해부구조를 그림으로 명료하게 나타낸 것으 로서 MR 합성영상인 (B)와 비교하면 매우 유사하다. 


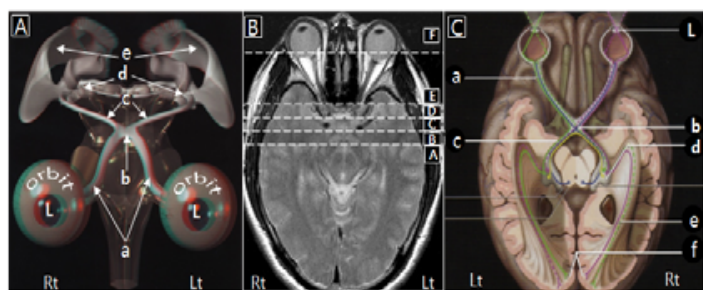

Fig. 2. (A): Optic nerve system model of human brain, (B): Overall image from $A$ to $F$ (a dotted line), (C): Axial graphic through visual pathway shows medial retinal fibers crossing in optic chiasm so that fibers from left half of both retinas course in left optic tract and fibers in right half of both retinas course in right optic tract (purple and green respectively). a: Optic nerve, b: Optic chiasm, c: Optic tract, d: Geniculate body, e: Optic radiation, f: Visual cortex, L: Lens, Rt: Right, Lt: left

\section{3. 다중각도 사위스캔}

Fig. 3은 우측 시각신경을 대상으로 영상선택단면 의 두께를 $3 \mathrm{~mm}$ 로 설정하고 시상선과 시각신경이 이 루는 시상-관상 (Sag>Cor) 단면방향과 횡 (Tra) 단면방 향으로의 기본각도를 설정한 것으로부터 Table 1 의 촬 영순서에 따라 각도를 변화해서 스캔한 영상이다. 이 영상들의 관심대상은 전체 시각신경계 구조로부터 나 타낼 수 있는 다중사위스캔에 필요한 적정 각도를 구 하기 위해 영상해부정보의 비교와 단면선택두께 및 펄스 시퀀스를 관찰하기위해 차례로 나열하였다 (scan No. \& images 1 0).

영상 1 4까지는 FSE 시퀀스를 이용한 T2WI이고, 5 6은 FSE 시퀀스에 지방신호를 억제 (fs)한 T2WI 이 다. 영상 (1 3)은 시상단면과 시각신경이 이루는 기본 각도를 시상-관상단면 방향으로 $37^{\circ}$, 횡단면방향을 $21^{\circ}$ 로부터 출발하여 각각 $2^{\circ}$ 씩 증가하며 스캔하여 영상 의 변화를 나타낸 것이다.

Fig. 3의 영상 (2)와 (3)은 각각의 방향으로 스캔각도 를 $2^{\circ}$ 씩 증가하여 스캔한 영상이다. 이들 두 영상을 비교해보면 영상 (2)는 시상-관상 단면방향 (Sag>Cor) 으로 $39^{\circ}$ 를 유지하고 횡단면 (Tra) 방향으로 $23^{\circ}$ 를 설 정하여 스캔한 것이며, 영상 (1)과 (3)보다는 조금 더 정확히 해부구조를 나타낸 것을 확인할 수 있다. 영상 (3)은 $\operatorname{Sag}>\operatorname{Cor}\left(42^{\circ}\right)>\operatorname{Tra}\left(25^{\circ}\right)$ 로써 스캔한 것으로서 영 상 (1)보다도 시각신경을 이루는 기본각도로부터 $5^{\circ}$ 증
가하였고, 횡단면으로도 $4^{\circ}$ 증가하여 시신경교차 부분 이 다른 조직과 더 겹쳐져 나타난 것으로 볼 수 있다.

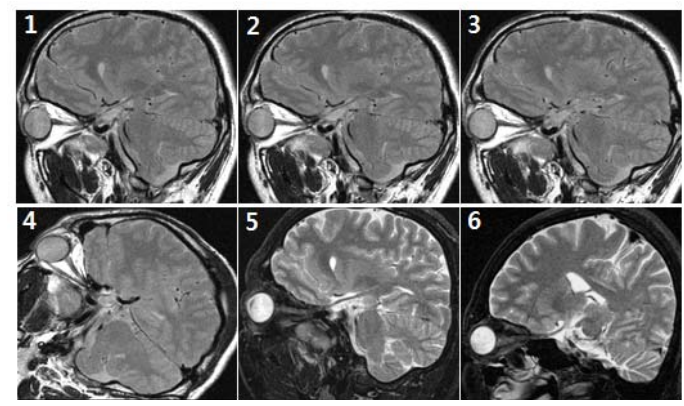

그Fig. 3. (1 4): Image of multi oblique scan angle change experimental results(FSE T2WI). (5): Relatively better image of optic nerve system structure among scan angle changes(FSE T2WI-fs). 6: Image of same scan angle but wrong establishment of scan direction (FSE T2WI-fs).

영상 (4)는 $\mathrm{Sag}>\mathrm{Cor}$ 방향으로 $46^{\circ}$, 횡단면 방향으로 $27^{\circ}$ 를 설정하여 스캔한 것으로서 과도한 스캔각도 때 문에 영상의 방향이 변하고 관심부위도 정확하게 보 여주지 못하고 있다. 영상 (5)는 Sag>Cor 방향을 $39^{\circ}$ 보 다 $1^{\circ}$ 증가한 $40^{\circ}$ 를 선택하는 대신에 $\mathrm{Tra}$ 방향의 각도 를 $28^{\circ}$ 로 선택하여 스캔한 영상이다. 영상단면의 두께 와 FSE-T2WI-fs 펄스 시퀀스를 사용한 결과로 역시 $\mathrm{SNR}$ 이 낮고, 시신경교차점 부근과 전방의 시각신경부 위가 더 어둡게 나타났음을 확인하였다.

영상 (6)은 상기의 우측 시각신경계에 대해 실험한 영상 중에 해부구조를 가장 잘 나타낸 영상 (5)의 펄스 시퀀스와 스캔각도를 선택하여 $\mathrm{Sag}>\operatorname{Cor}\left(40^{\circ}\right)>$ 는 변화 하지 않고, 횡단면 (Tra) 방향으로 설정한 양의 수를 부호만 반대 (-)로 입력하여 스캔한 영상이다. 이 영상 은 전체 시각신경계 중에 시신경교차점을 중심하여 목적 대상인 전방의 우측 시각신경은 정상적으로 보 여주고 있다. 그러나 그 후방의 영상은 좌측이 아닌 같은 우측방향의 시각로 및 무릎체 일부를 동시에 나 타냄으로서 영상 (4)와는 달리 해부정보가 무질서하게 혼재되어 있음을 인지할 수 있다. 이 영상으로부터 알 수 있는 것은 근본적으로 스캔방향을 바르게 설정하 지 않을 경우에는 심하게 왜곡된 영상정보를 제공한 다는 것을 확인할 수 있었다.

이상의 영상들을 전체적으로 살펴보면, 선택영상단 
면의 두께가 $3 \mathrm{~mm}$ 인 경우에 다중사위 스캔방법으로 써 시각신경계의 전체적인 해부구조를 가장 잘 보여 줄 수 있는 각도는 대략 $\operatorname{Sag}>\operatorname{Cor}\left(40^{\circ}\right)>\operatorname{Tra}\left(28^{\circ}\right)$ 를 설 정하여 스캔한 영상에서 Cho method의 적정한 스캔각 도의 범위를 확인할 수 있었다.

\section{4. 기존방법과 Cho method의 비교}

Fig. 4는 두부의 횡단면상에서 스캔계획단면은 굴곡 형태의 시각신경계에 대하여 시신경교차점을 중심하 여 수직한 인체 축으로부터 수평방향으로만 회전하여 시각신경이 직선상에 놓이게 되므로 주변의 상하 방 향만의 영상이 나타나게 된다. 그러므로 단면의 두께 로부터 벗어난 조직은 영상정보를 제공할 수 없게 됨 을 예측할 수 있다.

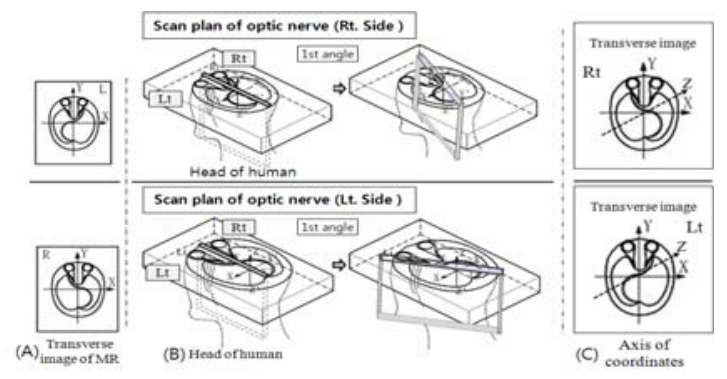

Fig. 4. Coordinates and illustration of conventional MR oblique scan method for left and right optic nerve image

Fig. 5는 두부의 정중시상단면으로부터 스캔계획 영 상단면을 시각신경계의 전체 해부구조를 포함하는 여 러 방향으로 경사각을 이루게 하여 다중사위 스캔을 위한 Cho method를 입체적으로 도해한 것이다. 이 그 림은 실제로 다중사위 스캔각도의 방향을 3 번 회전한 것을 모두 나타낸 것이다.

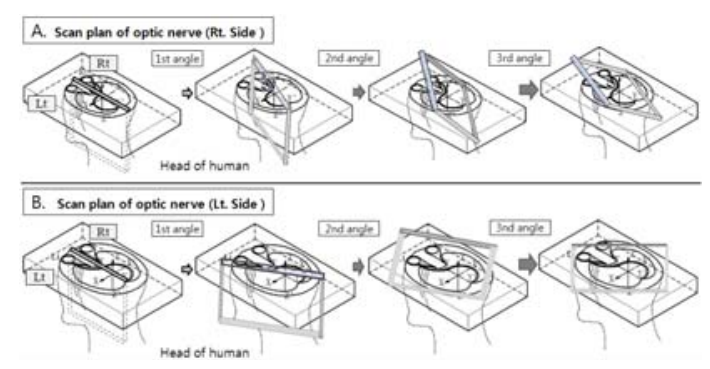

Fig. 5. Illustration of Cho method using slice selection gradient coil of MR system for left and right optic nerve system

\section{IV. 고찰}

질병의 정확한 진단을 위한 의료영상검사 및 결과 를 얻기 위해서 원칙적으로는 인위적으로 환자의 형 태적 해부구조와 내부정보를 왜곡하지 않고 최대한 많이 얻는 것이다. 그러나 인체는 해부구조상 굴곡 되 거나 3 차원적 입체구조를 형성하여 조직이 교차 또는 중첩되는 등 복잡한 형태를 이루고 있기 때문에 2차원 적 평면영상으로 모두 나타내기는 쉽지 않다. 특히 시 신경계는 위치가 각각 다르기 때문에 각 단면의 영상 에서 일부 제한적으로 나타나고 또 영상 단면의 간격 에 의해 정보의 손실이 발생한다. 이에 본 연구는 3 차 원 형태의 여러 방향으로 향하게 하는 다중사위 스캔 각도의 변화에 관하여 연구하였다. Fig. 6은 Table 2의 (No. 1)로써 SE T1WI-fs 시퀀스를 이용하여 우측 시각 신경을 시상단면으로부터 관상단면 방향 ( $\mathrm{Sag}>\mathrm{Cor})$ 으 로 시각신경이 이루는 기본각도 $\left(37^{\circ}\right)$ 로써 스캔한 단일 각도 사위 스캔방법으로써 나타낸 영상이다. 단면두께 는 $4 \mathrm{~mm}$ 로 하고 가산평균횟수를 2 번으로 수정하였다. 이 영상은 우측의 시각신경이 시신경교차점의 앞쪽 해부구조는 잘 나타내고 있다. 그러나 그 뒤쪽은 공간 좌표 상에서 곡선의 3 차원 해부구조를 형성하기 때문 에 단순히 직선상의 스캔각도를 유지하는 기존방식으 로서는 시각로 등을 포함할 수 없어서 2차원적인 한 평면상에 나타낼 수 없음을 확인할 수 있다. 그렇다고 하더라도 선택단면 두께를 너무 두껍게 하는 것은 한 영상에 전체 조직이 모두 포함되어 분해능이 낮아져 서 목적하는 조직의 구조를 판별하는 것이 거의 불가 능하다. Fig. 4 에서 예시한 바와 같이 우측 시각신경의 경우 시신경교차 점을 기준하여 그 전방에 위치한 우 측의 시각신경이 잘 나타나는 이유는 다음과 같다. 인 체를 후방에서 관측하면 우측을 향해서 전상 (anterior superior) 방향으로 비스듬히 주행하는 구조로 되어있 지만, 위에서 내려다본 모양은 직선을 이루기 때문이 다. 이것에 비해서 후방의 시각로와 시각로부챗살은 시신경교차점을 지나서부터 굴곡 형태를 이루어 영상 단면을 벗어나 있기 때문에 같은 단면상에 나타낼 수 없음을 알 수 있다. 그러므로 이 영상의 경우에는 횡 단면 영상과 단순히 방향만 다를 뿐, 시각신경의 좌우 를 대칭적으로 보여주는 횡단면 영상과 비교하면 오 
히려 제한적인 영상정보를 보여주고 있음을 확인할 수 있었다.

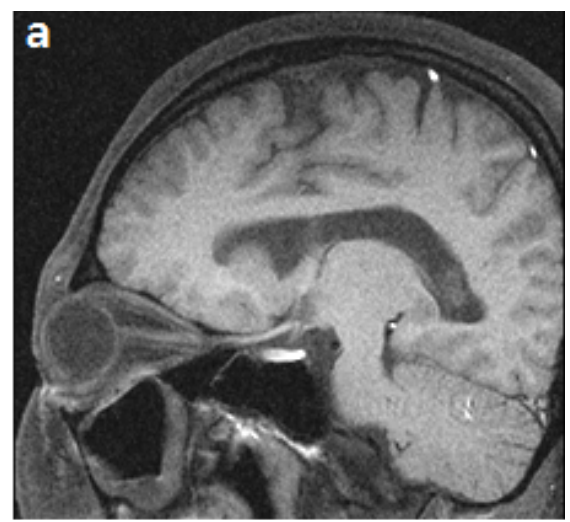

Fig. 6. Scan image by conventional oblique scan method with right optic nerve. SE T1WI-fs (a). Scan angle: (Sag $>$ Cor $\left(37^{\circ}\right)$

Fig. 7은 기존의 스캔방법과 같은 영상단면두께, 가 산평균횟수 그리고 SE T1WI-fs 시퀀스를 이용하여 우 측과 좌측의 시각신경을 Table 2의 다중사위 스캔방법 (Cho method: No. 2, 3)으로써 각각 나타낸 영상이다. (A)는 우측 시각신경계에 대하여 스캔각도를 $\mathrm{Sag}>\mathrm{Cor}$ $\left(41^{\circ}\right)>\operatorname{Tra}\left(29^{\circ}\right)$ 로 설정하여 나타낸 영상이다. 이것은 Table 1의 스캔 No. 5 의 스캔각도 $\left(\mathrm{Sag}>\operatorname{Cor}\left(40^{\circ}\right)>\operatorname{Tra}\right.$ $\left(28^{\circ}\right)$ 보다 $1^{\circ}$ 증가하여 근접하고, 그 결과인 Fig. 3 의 영 상 (5)과 매우 유사한 것을 확인할 수 있다. 여기에서 각도의 차이가 발생한 것은 스캔단면의 두께를 $4 \mathrm{~mm}$ 로 증가한 것과 약간의 허용오차 범위를 둔다면 다중 사위각도를 이용한 Cho method의 스캔방법으로써 매 우 적합한 각도의 선택임을 재확인할 수 있었다. 두께 와 펄스 시퀀스 등 영상의 $\mathrm{SNR}$ 의 차이를 제외하고 두 영상을 비교해보면 같은 다중사위스캔을 이용한 Cho method의 기법은 영상해부정보를 제공하는 양적인면 에서 유사하게 나타났으며, 기존의 사위스캔방법에 의 한 결과의 영상과는 분명한 차이를 확인할 수 있었다. (B)는 Cho method로써 좌측 시각신경계를 $\mathrm{Sag}>\mathrm{Cor}$ $\left(-38^{\circ}\right)>\operatorname{Tra}\left(-29^{\circ}\right)$ 로 선택하여 스캔 (Table 2, Scan No. 3) 한 영상이다. 이 스캔방법은 사위스캔의 각도가 모두 음 (-)의 부호로 설정되어있어서, Fig. 3에 나타난 영상 (6)의 스캔방법과 다르다는 것을 쉽게 확인할 수 있다. 결과적으로 Cho method를 이용한 좌측 시각신경계의 온전한 영상해부정보를 나타내기 위해서는 우측 시각
신경계를 나타내기 위한 스캔각도와 영상단면선택 방 향이 모두 정반대 방향으로 형성되어 있음을 실험으 로 확인하였다. 시각신경을 보기위한 스캔단면의 두께 는 $4 \mathrm{~mm}$ 가 적합한 것으로 생각하며 펄스 시퀀스는 $\mathrm{SE}$ $\mathrm{T} 1 \mathrm{WI}-\mathrm{fs}$ 를 이용하는 것이 유용함을 확인할 수 있었다.

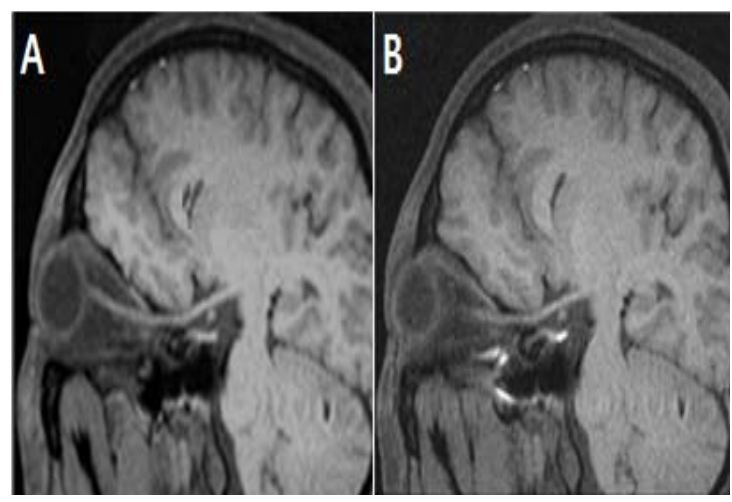

Fig. 7. Comparison SE T1Wl-fs images which is scanned from Cho method with left and right optic nerve Image (A): Sag $>$ Cor $\left(41^{\circ}\right)>\operatorname{Tra}\left(29^{\circ}\right)$, (Scan No. 2: Rt)

Image (B): Sag $>\operatorname{Tra}\left(-38^{\circ}\right)>\operatorname{Cor}\left(-29^{\circ}\right)$, (Scan No. 3: Lt)

Fig. 8은 시각신경계를 보기위한 기존의 사위스캔 방법으로써 나타난 영상 (Fig. 6, a)과 Cho method로써 나타난 영상 (Fig. 7, A)에 대하여 영상해부의 정보량을 비교하기위해 나타낸 영상이다. 이 두 가지의 영상 중 에 기존의 사위스캔 방법으로써 나타낸 영상 (Fig. 6. a) 은 시각신경과 시신경교차만 확인할 수 있다. 이에 비 교되는 Cho method로써 스캔한 영상은 시각신경, 시신 경교차는 기본적으로 나타나 있고, 시각로, 무릎체부 위, 시각부챗살도 일부 나타나 있는 것을 영상으로써 확인하였다. 상기의 실험으로부터 시신경교차점을 기 준으로 시각신경계의 영상을 $\pi$-view star 프로그램으로 써 측정하면 횡단면상에서 시각신경이 시상단면 방향 과 이루는 각도는 약 $35^{\circ} \sim 37^{\circ}$ 범위이다. 그러나 Cho method에서는 한 영상단면이 여러 방향을 향하도록 설정하기 때문에 실험에서 살펴본 결과에 의하면 이 각도는 횡단면방향으로도 경사를 이루게 되어 더 증 가하게 되는 것으로 사료된다. 


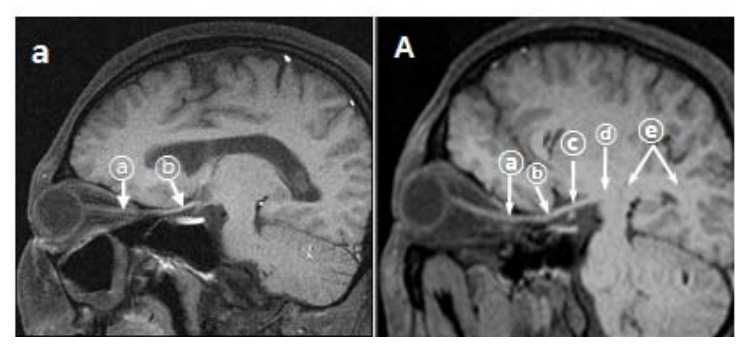

Fig. 8. Comparison image of conventional oblique scan method (Fig. 6. a) about right optic nerve with image of Cho method (Fig. 7. A). (white arrow), (a): optic nerve, (b): optic chiasma, (c): optic tract, (d): geniculate body, (e): optic radiation

이상의 연구 결과를 종합 분석해보면, MR로써 시각 신경계의 시상단면 다중사위영상을 보기위한 Cho method의 기준각도 설정은 기존의 스캔방법보다 더 많은 영상해부정보를 제공한다는 것을 확인하였다. 그 리고 인체 뇌구조 중 일부인 시각신경계를 좀 더 명료 하게 관찰할 수 있어서 흥미롭고도 의미 있는 실험연 구인 것으로 사료된다. 횡단면영상과 관상단면영상은 각각 한 단면상에서 좌우 대칭구조를 나타낸다. 횡단 면영상은 시각신경과 시각로 등이 상.하 간의 위치 차 이에 의해 각부의 조직이 순차로 나타날 뿐만 아니라 단면간격에 의한 정보손실도 발생 한다. 우 (또는 좌) 측의 시각신경 사위방향 영상을 보기위한 기존의 스 캔방법은 시각신경계에 대해서 시신경교차점을 기준 하여 전방에 위치한 시각신경은 잘 나타낼 수 있지만, 그 후방의 조직은 한 단면상에 나타나지 못한다. 이에 비해서 Cho method는 시각신경을 보기위한 기존의 시 상-관상단면의 단일방향 사위스캔 방법과 비교하여 전 체 시각신경계의 영상해부학적 정보를 더 많이 나타 내는 것을 확인하였다.

\section{$\mathrm{V}$. 결론}

한국의 성인 남성 두부외형의 평균치를 기준한 시 각신경계의 다중사위스캔 영상을 보기위한 Cho method의 실험결과로부터 적정 스캔각도를 구할 수 있었다. $\mathrm{MR}$ 의 자기장이 형성된 공간좌표를 기준하여 피검자가 바로누운자세에서 인체의 축 (z)이 주 자기 장 방향과 동일한 $\mathrm{Gz}$ 를 향하고 있을 경우에 해부학적 개인오차를 허용한다면 다음과 같은 결과에 이른다.

시각신경 다중사위영상을 보기위한 Cho method의
기본 스캔각도 및 형태는 다음과 같다.

\section{1. 우측 시각신경계를 스캔할 경우}

공간좌표 상으로 대략 정중 시상단면과 시각신경이 이루는 각도를 $38^{\circ} \sim 41^{\circ}$ 범위에 놓이게 하고, 횡단면 방향으로는 약 $28^{\circ} \sim 30^{\circ}$ 범위가 된다는 것을 확인하였 다. 이때 개략적인 영상선택단면의 올바른 경사방향은 Fig. 5 의 A와 같이 한 변이 피검자의 좌전간위 상방에 서 대각선방향으로 반대편의 우후간위하방을 유지해 야 한다.

2. 좌측 시각신경을 스캔할 경 우측 시각신경의 스 캔각도 범위에서 다만 음 (-)의 부호를 설정하여 시상 단면과 시각신경 그리고 횡단면으로 방향만 반대로 하면 거의 대칭적인 영상해부정보를 나타낼 수 있다. 이 경우의 올바른 선택단면의 경사방향은 Fig. 5 의 B 와 같이 한 변이 피검자의 우전간위 상방으로부터 반 대편의 대각선방향으로 좌후간위하방을 유지해야 한 다. 그리고 영상단면의 두께는 $4 \mathrm{~mm}$ 로 하고, 펄스 시 퀀스는 SE T1WI-fs을 이용하는 것이 더 유용한 것으로 사료된다.

\section{참고문헌}

[1] Philip W. Ballinger, "Merrill's atlas of radiographic positioning and radiologic procedures," Mosby Company. London, pp.362-426, 1928.

[2] Kang BK, Kam KY, Kwon OJ, Kim KT, " Neuroscience: Exploring the brain, Biomedbook. Korea, pp.171-175, 2009.

[3] Takahashi S, "Illustrated computer tomography," Springer-verlag. NY, pp.88-91, 1983.

[4] Takeda H, "MRI of extraocular orbital diseases: Comparison with CT," JJMR, Vol. 12, pp.388-400, 1990.

[5] Harnsberger HR, Wiggins RH, Hudgins PA, Michel MA, Swartz J, Davidson HC, Macdonald AJ, Glastonbury CM, Cure JK, Branstetter B, "Diagnostic imaging: Head and neck," Amirsys, Vol. 2, pp.59-75, 2004.

[6] Lee HK, Kang HJ, Kim EH, Kim CS, BAEK YW, Lee DM, Jeong HJ, Choi YJ, "Human anatomy," Komoonsa. Korea, pp.44-62, 2009.

[7] Martin C. Heisenberg, Tomas kramer, "Neuroanatomy: 3D-stereoscopic atlas of the human brain," Springer, pp.325, 1999. Saunders Company, China, Vol. 1, pp.219-222, 2006. 